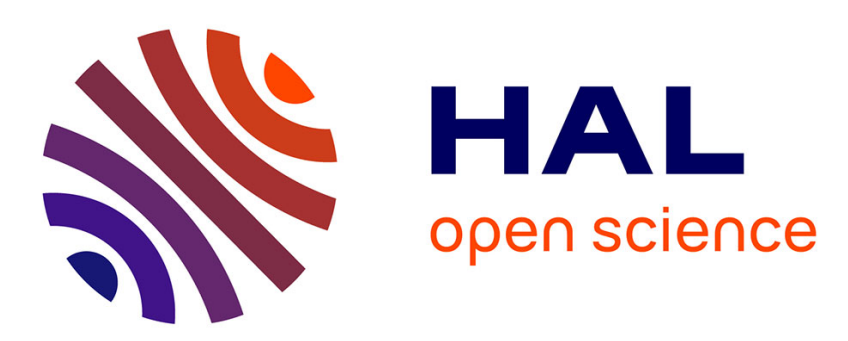

\title{
Motivational charateristics of obese adolescents toward physical activity: Contribution of self-determination theory
}

\author{
Mathieu Gourlan, David Trouilloud, Philippe Sarrazin
}

\section{- To cite this version:}

Mathieu Gourlan, David Trouilloud, Philippe Sarrazin. Motivational charateristics of obese adolescents toward physical activity: Contribution of self-determination theory. European Review of Applied Psychology / Revue Européenne de Psychologie Appliquée, 2013, 63 (4), pp.209-218. 10.1016/j.erap.2013.02.001 . hal-00947448v2

HAL Id: hal-00947448

https://hal.science/hal-00947448v2

Submitted on 17 Feb 2014

HAL is a multi-disciplinary open access archive for the deposit and dissemination of scientific research documents, whether they are published or not. The documents may come from teaching and research institutions in France or abroad, or from public or private research centers.
L'archive ouverte pluridisciplinaire HAL, est destinée au dépôt et à la diffusion de documents scientifiques de niveau recherche, publiés ou non, émanant des établissements d'enseignement et de recherche français ou étrangers, des laboratoires publics ou privés. 
1 Title: Motivational characteristics of obese adolescents toward physical activity: contribution

2

3 of self-determination theory

Titre : Caractéristiques motivationnelles des adolescents obèses vis-à-vis des activités physiques : une étude dans le cadre de la théorie de l'autodétermination.

Gourlan Mathieu

Trouilloud David, \& Sarrazin Philippe

Paper accepted by the the "Revue Européenne de Psychologie Appliquée/ European Review of Applied Psychology" 2013, 63(4), 209-218.

Corresponding authors :

Philippe Sarrazin or David Trouilloud, Laboratoire Sport et Environnement Social, Université Joseph Fourier - Grenoble 1, BP53, 38041 Grenoble CEDEX 9, France. E-mail:

philippe.sarrazin@ujf-grenoble.fr or david.trouilloud@ujf-grenoble.fr

Conflict of interest statement: We declare that we have no conflict of interest.

Remerciements : This research was funded with the joint help of the National Institute of Prevention and Health Education (INPES), the High Health Authority (HAS), the French national institute of health medical research and social system of independents, through the call for projects of the Research Institute in Public Health in 2007. 
1 Title: Motivational characteristics of obese adolescents toward physical activity: contribution

2 of self-determination theory

\section{Summary:}

4 Introduction: Regular physical activity (PA) practice represents a key component of obesity

5 treatment.

6 Objective: Based on Self-determination theory, this cross-sectional study aimed to explore the

7 motivational characteristics associated with PA practice among obese adolescents.

8 Method: One hundred and five overweight or obese adolescents (Mean age $=15$ years old, SD

$9=2.69$ ) were questioned about their (a) level of PA, (b) motivational regulations toward PA and (c) level of satisfaction of basic psychological needs.

Results: Data revealed that satisfaction of autonomy and relatedness needs is positively associated with autonomous forms of motivation (e.g., for integrated regulation $\beta=.44$; and .35 , respectively, $p<.01)$. Otherwise, non-satisfaction of the needs of autonomy and competence is associated with the most controlled forms of motivation (e.g., for external regulation $\beta=-.27, p<.01$; and $-.18, p<.05$, respectively). In turn, an high level of identified regulation, a low level of external regulation and an high level of satisfaction of the need for competence are associated with weekly PA $(\beta=.28 ;-.19$ and .24 , respectively, $p<.05)$.

Conclusion: SDT appears as an interesting theoretical framework to explore motivational antecedents of PA among obese adolescents.

Running title: Motivation and physical activity of obese adolescents

Key-words: Physical activity, Motivation, Adolescence, Obesity, Self-determination theory 
1 Titre : Caractéristiques motivationnelles des adolescents obèses vis-à-vis des activités

2 physiques : une étude dans le cadre de la théorie de l'autodétermination.

3 Résumé :

4 Introduction : La pratique régulière d'activités physiques (AP) représente une composante

$5 \quad$ essentielle du traitement de l'obésité.

6 Objectif : S'appuyant sur la théorie de l'autodétermination, cette étude transversale avait pour 7 objectif d'évaluer les caractéristiques motivationnelles associées à la pratique d'AP chez des 8 adolescents obèses.

9 Méthode : Cent-vingt cinq adolescents obèses ou en surpoids (âge moyen $=15$ ans, ET =

2.69) ont été interrogés sur (a) leur temps de pratique hebdomadaire, (b) leurs régulations motivationnelles pour l'AP et (c) leur niveau de satisfaction des besoins psychologiques fondamentaux.

Résultats : Les analyses révèlent que la satisfaction des besoins d'autonomie et de proximité sociale est positivement associée aux formes autodéterminées de motivation (e.g., pour la régulation intégrée $\beta=.44$; et .35 , respectivement, $p<.01$ ). Par ailleurs, la non-satisfaction des besoins d'autonomie et de compétence est associée aux formes les plus contraintes de motivation (e.g., pour la régulation externe $\beta=-.27, p<.01$; et $-.18, p<.05$, respectivement). En retour, une forte régulation identifiée, une faible régulation externe et un niveau élevé de satisfaction du besoin de compétence sont associés au temps d'AP hebdomadaire $(\beta=.28$, .19 et .24 , respectivement, $p<.05)$.

Conclusion : La TAD est un cadre explicatif intéressant afin d'explorer certains antécédents motivationnels de la pratique chez les adolescents obèses.

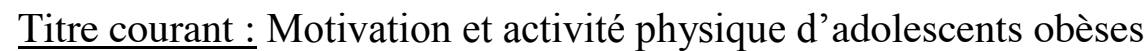

Mots-clés : Activités Physiques, Motivation, Adolescence, Obésité, Théorie de l'autodétermination 


\section{Introduction}

The number of obese and overweight children and adolescents has reached a high

level in recent years. In France around 16\% are overweight and 3\% obese (Salavane, Peneau, Rolland-Cachera, Hercberg, and Castetbon, 2009). Such findings are a concern with regard to the medical (e.g. type 2 diabetes) and psychosocial (e.g. low self-esteem) consequences associated with excess weight in childhood and adolescence (Pi-Sunyer, 2002). It is mainly for this reason that the treatment of pediatric obesity is a public health priority (Inserm, 2007). Physical Activity (PA), in association with certain eating behaviors, is recommended for the treatment and long-term management of excess weight (Parizkova and Hills, 2001). Recent meta-analyses report a significantly greater impact on weight loss of programs combining diet and PA compared to programs based solely on dieting (e.g., Wu, Gao, Chan, et Van Dam, 2009). However, despite the health benefits of PA, obese adolescents experience difficulties in adopting an active lifestyle: studies reveal that a majority participates in less than 20 minutes PA per day (e.g., Eagle et al., 2010). This level of participation turns out to be less than the one hour of PA per day currently recommended for this population (World Health Organization, 2012). Thus, it seems necessary to understand better the reasons for this population's engagement or non-engagement in regular exercise.

Insert figure 1 about here

Based on Self-Determination Theory (SDT; Deci and Ryan, 2002; see Sarrazin, Pelletier, Deci, and Ryan, 2011, for an overview in French), this study aims to explore the motivational characteristics of obese adolescents toward PA. As figure 1 shows, SDT offers a motivational sequence in which the satisfaction of psychological needs is indirectly associated with PA through different motivational regulations. Six types of motivation are assumed to differ according to the degree in which the behavior is carried out voluntarily, by real choice (i.e. self-determined) or in response to pressure (Ryan and Deci, 2000). From the most self- 
1 determined motivation to the least we find: intrinsic regulation (engagement in an activity for

2 the inherent pleasure associated with it), integrated regulation (engagement in an activity for

3 its coherence with the practitioner's character and values), identified regulation (engagement

4 in an activity for reasons of its importance and usefulness), introjected regulation

5 (engagement in an activity in response to internal pressure such as a feeling of guilt) and

6 external regulation (engagement in an activity in response to external pressure such as the

7 promise of a reward). The theory also proposes the existence of a state of amotivation, which

8 occurs when an individual has not identified any particular reason to engage in a behavior.

SDT also specifies the conditions that may affect motivation. According to the theory, the environmental conditions that fulfill the need for autonomy (i.e., feeling responsible for one's actions), relatedness (i.e., feeling respected, included and valued by significant others) and competence (i.e., feeling a sense of mastery through effective interaction within the environment) promote the development of self-determined forms of motivation. In contrast, environmental conditions affecting the satisfaction of these needs favor controlled forms of motivation and amotivation (Ryan and Deci, 2000).

Recent meta-analysis carried out in various health domains (e.g. smoking cessation, obesity) has confirmed that the satisfaction of psychological needs is associated with selfdetermined forms of motivation (i.e. intrinsic, integrated and identified regulations), in turn associated with positive consequences (e.g., greater participation in PA) (Ng et al., 2012). In contrast, the absence of the satisfaction of psychological needs is more associated with controlled forms of motivation (i.e. introjected and external regulations) and amotivation, in turn associated with negative consequences (e.g., a low level of PA). Studies carried out on obese populations (e.g., Edmunds, Ntoumanis, and Duda, 2007; Silva et al., 2010) have also confirmed relationships existing between psychological needs, motivational regulations and PA. 
1

However, some areas remain unexplored. Several authors (e.g., Teixeira, Carraça, Markland, Silva, and Ryan, 2012) have, for example, highlighted the lack of work on the 'specific' role of each need and each regulation on PA. In fact, to limit the number of variables included in the statistical analysis, a majority of the works bring the various motivational regulations together in the form of two indices, reflecting respectively selfdetermined versus controlled form of motivation (e.g., Fortier, Sweet, O’Sullivan and Williams, 2007), and even a single self-determination index (Hagger, Chatzisarantis, and Harris, 2006). Similarly, some studies have combined the three psychological needs as a single indicator (e.g., Quested et al., 2011).

In order to improve the understanding of the motivational characteristics associated with engagement in an active lifestyle, it seems necessary to explore the specific relationships between psychological needs and the different motivational regulations on the one hand, and between motivational regulations and PA on the other. This study aims specifically to explore the motivational sequence proposed by SDT, by focusing on three objectives. The first objective is to determine - among obese adolescents - the specific relationship between the satisfaction of psychological needs associated with participation in PA and motivational regulations towards this participation. The second objective is to determine the relationship between the various regulations and PA for these adolescents. Finally, the third objective is to assess the motivational sequence in its entirety and in particular to test the mediating role of motivational regulations in the relationship between psychological needs satisfaction and PA. The following paragraphs present hypotheses associated with these objectives and the reasons which underlie them.

Hypotheses on the relationship between the satisfaction of psychological needs and motivational regulations (Objective 1). Intrinsic motivation requires spontaneous attraction towards an activity that conveys a challenge and the possibility of testing one's skills (Deci 
1

and Ryan, 2000), a positive relationship is expected between this form of motivation and the

2 satisfaction of needs for autonomy and competence. Given the many examples of PA

3 participated in alone (e.g., running), satisfaction of the need for relatedness should be less (or

4 not) connected to intrinsic motivation. In contrast, amotivation and external regulation should

5 be negatively associated with the satisfaction of the three needs (Deci and Ryan, 2002), with a

6 stronger relationship for amotivation. Introjected, identified and integrated regulations are

7 different stages of the process of assimilation of values or external demands, perceived as

8 useful by the individual (Deci and Ryan, 2000). Introjection is an incomplete assimilation

9 behavior which results from a conflict between two needs: the desire to please someone to

whom one feels close (i.e. satisfy the need for relatedness) and the lack of volition with

respect to that behavior (i.e. non-satisfaction of the need for autonomy) (Koestner and Losier, 2002). Identification and integration are the final stages of the assimilation process and require the simultaneous satisfaction of the three needs (Deci and Ryan, 2000), with a stronger relationship for integrated regulation, including the need for autonomy. These assumptions are summarized in Table 1.

\section{Insert Table 1 about here}

Hypotheses on the relationship between motivational regulations and PA (Objective 2). While the three self-determined forms of regulation are expected to be positively related to PA, we assume that identified and integrated regulations are more closely associated with PA in obese adolescents than intrinsic motivation. According to some earlier works, the fun or pleasure inherent to PA could be experienced less in this population (Edmunds, Ntoumanis, and Duda, 2006, 2007). Furthermore, although introjected regulation is associated with various adverse consequences (e.g., anxiety) (Thøgersen-Ntoumani and Ntoumanis, 2006), some recent studies have demonstrated a positive association between this form of motivation and PA for overweight and/or obese people (e.g., Edmunds et al., 2007). Introjection could therefore 
1 stimulate the behavior, at least in the short term (Teixeira et al., 2012), a positive relationship

2 to PA is therefore expected. Finally, consistent with the theory and previous work (e.g.,

3 Brunet and Sabiston, 2011), external regulation and amotivation should be negatively

4 associated with PA.

$5 \quad$ Hypotheses on the mediating role of motivational regulations in the relationship between

6 psychological needs satisfaction and PA (objective 3). According to the premises of SDT

7 (e.g., Deci and Ryan, 2002), the satisfaction of the three psychological needs is indirectly

8 associated with PA through different motivational regulations (cf. figure 1). In other words,

9 the statistical consideration of potential mediators should make the relationship between psychological needs and PA disappear or diminish.

\section{Method}

\section{Procedure and participants}

One hundred and twenty five adolescents (54 male, 71 female, age range $=11-18$ years, $\mathrm{SD}=2.69$ ) with a body mass index for age and sex (i.e., BMI Z-score) corresponding to overweight or obese, according to French standards (PNNS, 2001) participated in this study. In France, the threshold for overweight is defined as a BMI Z-score greater than 2 $\left(\mathrm{BMI}>97^{\text {th }}\right.$ percentile), and for obesity as a Z-score greater than 3 (Rolland-Cachera and Thibault, 2002).

Adolescents were recruited in the Rhône-Alpes (Lyon, Grenoble and Annonay) region of France, in three centers for the treatment of pediatric obesity. All were initially referred to these centers by their General Practitioners or school doctor because of their high BMI. Sixty of them (48\%) were overweight and $65(52 \%)$ obese. In each of these centers, care for the adolescents consisted of group sessions of about 2 and a half hours with various activities (e.g., health education) and approximately one hour of supervised PA (e.g., team games). The adolescents attended these centers on a weekly or fortnightly basis. 
1

Authorization was obtained from parent(s) or guardian(s) for each participant one month before the start of the study. After a presentation of the objectives of the study (i.e., a survey of the adolescents' PA), participants completed a consent form in which they were informed of their rights and in particular (1) the non-obligatory, anonymous and confidential nature of the questionnaire, (2) the right not to answer questions they considered embarrassing and (3) the possibility of stopping the questionnaire at any time. Volunteer participants then completed the questionnaire over a twenty minute period, during group sessions of about 10 people, supervised by a staff member from the center (e.g., a psychologist, a dietician or a nutritionist).

\section{Measures}

Physical activity. The Physical Activity Questionnaire for Adolescents (PAQ-A, Kowalski, Crocker, and Kowalski, 1997) was used to measure the weekly moderate to high PA participation of every teenager. Specifically, adolescents were asked about the duration of their participation in recreational, sporting and in everyday life activities. For this, participants mentioned the specific name of the activities carried out and the frequency and duration of participation during a typical week. Concrete examples were given for each type of PA (e.g., walking to school, jogging). The duration of participation in hours per week was then calculated. Previous studies have confirmed the validity and reliability of the PAQ-A (e.g., Crocker, Bailey, Faulkner, Kowalski and McGrath, 1997; Kowalski et al., 1997). Motivations for PA. The French version of the Behavioral Regulation Exercise Questionnaire (BREQ-2) (Markland and Tobin, 2004) was used to assess motivation towards PA. This 20item scale assesses the reasons why people exercise or participate in PA. The BREQ-2 includes subscales assessing intrinsic (e.g., I exercise because it's fun”), identified (e.g., "I think it is important to make the effort to exercise regularly"), introjected (e.g., "I feel guilty when I don't exercise"), external (e.g., "I take part in exercise because my friends/family say I 
1 should") regulations, and amotivation (e.g., "I don't see why I should have to exercise").

2 Following the stem "Why do you engage in exercise?" participants respond to each item on a

3 7-point scale ranging from 1 ("not true for me") to 7 ("very true for me"). In addition,

4 integrated regulation was assessed through 4 items (e.g., "I consider exercise to be part of my

5 identity"; Wilson, Rodgers, Loitz, and Scime, 2006).

6 Perceived self-efficacy toward PA. Self-efficacy, a central component of the need for

7 competence as conceptualized in SDT (Deci, 1975), was evaluated in this study following the

8 recommendations made by Bandura (1997). Four items were used to measure the participants'

9 degree of confidence in their ability to participate in at least 30 minutes of moderate to intense PA, one, two, three and four times a week. For each item, participants indicated their level of confidence on a 100 point scale, from $0 \%$ ("absolutely not confident") and 100\% ("absolutely confident"). An overall score of self-efficacy toward PA was then calculated from the average of the scores for the four items. Previous work (e.g., Everett, Salamonson and Davidson, 2009) reported the validity and reliability of this scale for people with chronic illness.

Perceived autonomy toward PA. The adolescents' feeling of autonomy toward PA was measured using a scale based on the work of Reeve, Nix, and Hamm (2003). Given that a psychological need can be satisfied versus frustrated (e.g., Deci and Ryan, 2000), we used a bipolar scale. Following the phrase "When I participate in PA, generally ...", participants were asked to respond to each of the five items using a 7-point scale ranging from (1) (e.g., "I feel pressured") to (7) (e.g., "It is me who decided"). Previous works have demonstrated the validity and reliability of this scale with adolescents participating in a sport (e.g., Cheval and Sarrazin, 2011) and adolescents with eating disorders (e.g., Bateman, 2012).

Perceived relatedness toward PA. A scale composed of three items based on previous work (e.g., Wilson, Rogers, Rodgers, and Wild, 2006) was used to measure the level of perceived relatedness to other participants (e.g., "I consider the people with whom I participate in a 
1 physical activity as my friends"). Participants were asked to indicate their level of agreement

2 for each item on a 7-point scale ranging from (1) "strongly disagree" to (7) "strongly agree".

$3 \quad$ Statistical analyses

After examining the internal consistency of the various scales, descriptive statistics were calculated for each variable. We then used a combined procedure following the various steps proposed by Baron and Kenny (1986) for testing a mediation, as well as the procedures described by Preacher and Hayes (2008) for assessing the total, direct and indirect effects of an independent variable on a dependent variable, through multiple mediators. This approach was chosen in order to specifically test our hypotheses regarding, on the one hand, the relationship between the needs and the motivational regulations, and on the other, the relationship between the motivational regulations and PA, before specifically testing for the presence of a multiple mediation (see Teixeira et al., 2010, for a similar approach). For all the analyses the significance threshold was set at $p<.05$. A statistical trend was considered at $p$ $<.10$. Firstly, and in accordance with Baron and Kenny (1986), we checked whether the independent variables (i.e., psychological needs) were significantly associated with the mediator variables (i.e., motivational regulations). For this, the Bravais Pearson correlation analysis and six multiple regression analyses (each regulation was regressed on the three psychological needs) were performed. In a second step, we checked whether the mediator variables were associated with the dependent variable (i.e., PA length), from similar analyses. Statistica 7.1 software was used for all of those analyses.

Thirdly, in order to test the model proposed specifically for multiple mediations, we used the Preacher and Hayes (2008) bootstrapping procedure to obtain an estimate of the direct, indirect and total effects. Bootstrapping is a nonparametric resampling procedure for estimating indirect effects using adjusted (asymmetric) confidence intervals. This procedure is very useful in cases of multiple mediations, for which it is interesting to determine not only 
1 whether an indirect effect exists, but which mediator(s) contribute(s) significantly to the

2 effect. This method is also particularly suitable when the sample size is not very large

3 (Preacher and Hayes, 2008). In these analyses we have retained the motivational regulations

4 that related significantly to PA identified in the second step. In fact, given the considerable

5 overlap between the motivational regulations, it is not recommended to leave multiple

6 variables that are not significantly related to the dependent variable in the regression analyses.

7 They create instability in the regression coefficients and can make models particularly

8 difficult to interpret (Cohen and Cohen, 1983). Preacher and Hayes also recommend selecting

9 mediators having as small a conceptual overlap as possible to minimize problems of

collinearity. Bootstrap analyses were performed using SPSS 20 and the macro developed by

Preacher and Hayes (2008). As this macro does not allow multiple independent variables to be tested at the same time, three analyses were necessary (one for each need). 95\% biascorrected confidence intervals, and 1000 bootstrap samples with replacement were requested.

Finally, the indirect effects ratio was calculated to express the amount of the total effect explained by the indirect effect (i.e., by the mediators). According to Shrout and Bolger (2002), it is preferable to express the effects of mediation quantitatively rather than in the usual dichotomous form (i.e., "complete" versus "partial" mediation). For example, an indirect effect ratio of 0.5 means that half of the total effect of the independent variable on the dependent variable is explained by the mediator(s).

\section{Results}

\section{Preliminary analyses}

The descriptive statistics and the correlation coefficients between the various variables are presented in Table 2. Internal consistency is satisfactory for all the scales $(\alpha>.70)$, apart from introjected regulation $(\alpha>$.65). On the whole the various variables respect a normal distribution, except for the amotivation scale. The amount of self-reported PA is particularly 
1 high $(\mathrm{M}=6.30$ hours per week), with however, a high standard deviation ( $\mathrm{SD}=1.44)$,

2 indicating considerable variability between the participants. The correlations between the

3 motivational regulations largely confirm the simplex structure of the self-determination

4 continuum (Ryan and Connell, 1989), with higher correlation coefficients between

5 conceptually proximal regulations, compared to the correlations between conceptually distant

6 regulations. Compared with girls, boys reported higher scores for perceived relatedness,

7 intrinsic motivation, integrated regulation, identified regulation, external regulation and PA ( $r$

8 between .20 and $.33, p<.05)$. Finally, it should be noted that the most corpulent adolescents

9 reported lower scores for perceived self-efficacy, perceived relatedness, and PA participation

10 ( $r$ between these variables and BMI between -.23 and $-.27, p<.05)$, and a higher external

11 regulation score $(r=.26, p<.01)$. Therefore, BMI and gender were included as control

12 variables in subsequent analyses.

\section{Insert table 2 about here}

\section{Relationships between the satisfaction of psychological needs and motivational regulations}

The correlation coefficients between the six motivational regulations and the satisfaction of the three psychological needs are presented in Table 2. These results show a positive relationship between the satisfaction of the three needs and intrinsic $(r$ between .37 and $.67, p<.01)$, integrated ( $r$ between .24 and $.56, p<.01)$ and identified regulations $(r$ between .33 and $.46, p<.01)$. In contrast, the needs are negatively related to amotivation $(r$ between -.18 and $-.44, p<.05)$ and to external regulation $(r=-.27$ and -.28 with autonomy and self-efficacy, respectively, relatedness not correlating with this regulation). Finally, introjected regulation only correlates with perceived autonomy $(r=.25, p<.01)$.

Six multiple regression analyses were then carried out, in which each motivational regulation was regressed on the three needs, gender and BMI (Table 3). The analyses show that intrinsic, integrated and identified regulations are positively associated with the 
1 satisfaction of needs for autonomy $(\beta=.55, .44$, and .30 , respectively, $p<.01)$ and relatedness

$2(\beta=.17, .35$, and .25 , respectively, $p<.05)$. Moreover, introjection is positively associated

3 with the satisfaction of the need for autonomy $(\beta=.26, \mathrm{p}<.01)$ and negatively (as a trend)

4 with perceived self-efficacy $(\beta=-.17, p<.10)$. External regulation is negatively associated

5 with perceived self-efficacy $(\beta=-.18, p<.05)$ and perceived autonomy $(\beta=-.27, p<.01)$ and

6 positively with the satisfaction of the need for relatedness $(\beta=.21, p<.05)^{1}$. Finally,

7 amotivation is negatively associated with perceived self-efficacy $(\beta=-.29, p<.01)$ and

8 perceived autonomy $(\beta=-.33, p<.01)$. These various analyses predict between $6 \%$ (for

9 introjection) and 54\% (for intrinsic motivation) of the variance of the motivational regulations

\section{Insert Table 3 about here}

\section{Relationships between motivational regulations and participation in PA}

The correlation coefficients between the motivational regulations and PA participation

(see Table 2) show a positive relationship between the three self-determined forms of

motivation (i.e., intrinsic, integrated and identified) and PA $(r=.40, .43$, and .44 ,

respectively, $p<.01$ ), and a negative relationship between the two least self-determined forms

of motivation (i.e., external regulation and amotivation) and PA ( $r=-.23$ and $-.24, p<.01$,

respectively). Only introjected regulation is not significantly correlated with PA. To assess the specific contribution of motivational regulations, PA was then regressed on the six motivational regulations, gender and BMI (Table 4). The results show that PA is positively associated with identified $(\beta=.36, p<.01)$ and (as a trend) intrinsic regulations $(\beta=.21, p$ $<.10)$, and negatively related to external regulation $(\beta=-.21, p<.05)$. These three regulations predict $27 \%$ of the variance in PA.

Insert Table 4 about here 
1

2

3

4

5

6

7

8

9

10

11

12

13

14

15

16

17

18

19

20

21

22

23

24

25

Mediating role of motivational regulations in the relationship between psychological needs satisfaction and PA

The preceding analyses reveal, on one hand, relationships between the independent variables (i.e., psychological needs) and the mediating variables (i.e., motivational regulations), and on the other, relationships between certain mediating variables (intrinsic, identified and external regulations) and the dependent variable (i.e., PA). To test for the presence of a multiple mediation, three bootstrap analyses were conducted in which each need was considered in turn as the independent variable, intrinsic, identified and external regulations as mediators, and PA as the dependent variable. BMI, gender and the other two needs were used as control variables.

The first bootstrap analysis shows that the total effect of the satisfaction of the need for autonomy on PA $(0.55)$ is significant $(t=1.99, p<.05)$, whereas the direct effect $(0.07)-$ when the mediators are controlled - is not $(t=0.20, p>.83)$. Moreover, the satisfaction of the need for autonomy is significantly related to the three motivational regulations $(\mathrm{B}=0.64$, 0.33 , and $-0.31, p<.01$, respectively, for intrinsic, identified and external regulations). Among these mediators, only identified $(\mathrm{B}=0.63, p<.05)$ and external $(\mathrm{B}=-0.52, p<.05)$ regulations are significantly related to PA. As Table 5 shows, the total indirect effect $(0.48)$ is significant because the $95 \%$ bias adjusted confidence interval does not contain the value zero (0.05 - 1.04). A mediating effect ratio of 0.87 is observed, which means that about $87 \%$ of the total relationship between the need for autonomy and PA is explained by the mediators. The magnitude of this ratio, associated with a non-significant direct effect when the mediators are controlled, suggests the presence of a strong mediation effect (or a full mediation in the usual terminology). However, of the 3 individual indirect effects, only 2 are significant (Table 5): the effect of the satisfaction of the need for autonomy on PA is mediated by identified (indirect effect $=0.21)$ and external regulations (indirect effect $=0.16$ ). 
1

The second bootstrap analysis shows that the total effect of perceived self-efficacy on

2 PA (0.05) is significant $(t=2.91, p<.01)$. However, the direct effect $(0.04)-$ when the

3 mediators are controlled - is still significant $(t=2.19, p<.05)$. Moreover, perceived self-

4 efficacy is only significantly related to external regulation $(\mathrm{B}=-0.01, p<.05)$. Of the three

5 mediators, only identified $(\mathrm{B}=0.63, p<.05)$ and external regulations $(\mathrm{B}=-0.52, p<.05)$ are

6 significantly related to PA. As Table 5 shows, the total indirect effect $(0.012)$ is significant. A

7 mediating effect ratio of 0.25 was observed, which means that about $25 \%$ of the total

8 relationship between perceived self-efficacy and PA is explained by the mediators. The

9 magnitude of this ratio, associated with a still significant direct effect when the mediators are controlled, suggests the presence of a partial mediation (in usual terminology). Of the 3

individual indirect effects, only 1 is significant (Table 5): the effect of the feeling of perceived self-efficacy on PA is partially mediated by external regulation (indirect effect $=0.006$ ).

The third bootstrap analysis shows that the total effect of satisfying the need for relatedness on PA $(0.51)$ is significant (as a trend) $(t=1.78, p<.08)$, whereas the direct effect $(0.43)$ - when the mediators are controlled - is not $(t=1.44, p>.15)$. In addition, meeting the need for relatedness is significantly related to the three motivational regulations $(\mathrm{B}=0.21$, 0.28 , and $0.25, p<.05$, respectively, for intrinsic, identified and external regulations). Of the three mediators, only identified $(\mathrm{B}=0.63, p<.05)$ and external regulations $(\mathrm{B}=-0.52, p$ $<.05)$ are significantly related to PA. As Table 5 shows, the total indirect effect $(0.04)$ is not significant. Of the 3 individual indirect effects, only two are significant: the effect of satisfying the need for relatedness on PA is positively mediated by identified regulation (indirect effect $=0.18$ ) and negatively by external control (indirect effect $=-0.13$ ). These opposing mediator effects reflect the presence of a suppression effect, confirmed by the lack of significance of the total indirect effect (Preacher and Hayes, 2008). In these circumstances, 
1 the ratio of 0.17 for the mediating effect does not make much sense since the calculation starts

2 from the principle that there is no suppression effect (Shrout and Bolger, 2002).

Overall, the multiple mediator model is significant $[F(8,115)=7.87, p<.001]$ and explains $35 \%$ of the variance for PA. Figure 2 summarizes the significant results of the different analyses.

Insert Table 5 and Figure 2 about here

\section{Discussion}

Drawing on SDT (Deci and Ryan, 2002), this study, conducted among 125 overweight or obese adolescents, explored the motivational sequence linking the satisfaction of psychological needs, motivational regulations and PA. More specifically, this study aimed to determine (1) the specific relationship between the satisfaction of three psychological needs and motivational regulations, (2) the relationship between the different motivational regulations and participation in $\mathrm{PA}$, and (3) the mediating role of motivational regulations in the relationship between psychological needs satisfaction and PA. Unlike most earlier studies, the singular role of each need and motivational regulation was thoroughly examined. The results are discussed in relation to these three objectives.

\section{Relationships between psychological needs satisfaction and motivational regulations}

The results generally confirm our hypotheses concerning the specific relationship between the satisfaction of psychological needs and the different motivational regulations toward PA. Firstly, intrinsic motivation has been shown to be more associated with the satisfaction of the need for autonomy than with the satisfaction of the need for relatedness.

Such a result thus confirms the necessity for individuals to feel free in their choice in order to feel an inherent interest in the activities they participate in (Deci and Ryan, 2000).

Nevertheless, the existence of a significant relationship between the satisfaction of the need for relatedness and intrinsic motivation indicates that for obese teenagers, intrinsic motivation 
1 is more likely to thrive in contexts characterized by strong and secure social relationships.

2 Secondly the satisfaction of the need for autonomy and relatedness was positively related to

3 integrated and identified regulations with a stronger relationship for the first. The more the

4 needs for autonomy and relatedness were satisfied, the more the adolescents tended to be

5 motivated towards PA because they had identified the benefits (identified regulation) and / or

6 because PA was constitutive to their values and personality (integrated regulation). This last

7 result confirms that integrated regulation reflects a higher level of assimilation than identified

8 regulation, on both an intrapsychic (i.e., feeling of choice and higher-order volition) and a

9 social (i.e., feeling of relatedness to other higher-level practitioners) level (Deci and Ryan, 2000). Finally, the lower the levels of perceived self-efficacy and perceived autonomy, the more the adolescents questioned the interest of participating in PA (amotivation) or tended to be motivated towards PA because of external pressure (external regulation).

Other results reported in this study have not, however, fully confirmed our hypotheses.

Firstly, it should be noted that the significant relationship between certain needs and certain regulations disappears when the other two needs are statistically controlled. In fact, the analyses revealed that, despite the existence of significant correlation coefficients, the relationship between perceived self-efficacy and identified, integrated and intrinsic regulations are no longer significant when other needs are controlled. A similar result was found for the relationship between the need for relatedness and amotivation. Given the relatively high correlations between different needs (e.g., $r=.41$ between perceived selfefficacy and perceived autonomy), such results can be explained by the overlap between these variables. It is also possible that these results are specific to this population. For example, Edmunds et al (2007) also reported the absence of a relationship between the satisfaction of the need for competence and identified and integrated regulations in adults with obesity. In view of these results, further research appears necessary in order to continue the exploration 
1 of the relationship between psychological needs and motivational regulations in this

2 population.

3

4

5

Secondly, the analyses revealed an unexpected positive relationship between satisfaction of the need for relatedness and external regulation. Despite the absence of correlation between these 2 variables, a positive relationship was found when the external regulation was regressed on the three psychological needs. Additional analyses together with mediation analyses (see below) confirmed that this result was due to a suppression effect (Pandey and Elliott, 2010). Finally, the results for the relationship between the needs and introjected regulation is not entirely consistent with our hypothesis. While they confirm that this first level of assimilation behavior results from a conflict between two needs (Deci \& Ryan, 2000), the needs involved are not those presumed. We expected introjected regulation to be related to a high level of satisfaction of the need for relatedness and a low satisfaction of the need for autonomy. The results show that for obese adolescents in this study, the stronger presence of introjected regulation towards PA was linked to a conflict between the satisfaction of the need for autonomy (i.e., the adolescent feels responsible for choices in terms of PA) and the lack of satisfaction of the need for competence (i.e., the adolescent experiences a low level of self-efficacy in achieving the recommended PA thresholds for health benefits). This situation increases the internal pressure and the feeling of guilt with regard to PA. Additional work is recommended in order to explore this unprecedented result further.

\section{Relationships between motivational regulations and PA}

Overall, the results confirm our hypotheses on the relationships between the various motivational regulations and PA. First of all, PA has been more (positively) associated with identified regulation than intrinsic motivation. This result suggests that obese adolescents do not necessarily engage in active lifestyles for intrinsic reasons such as pleasure or pleasurable sensations but rather for the perceived benefits of PA, particularly in terms of well-being and 
1 health (i.e., identified regulation). Nevertheless, while not systematically associated with

2 actual participation in sedentary populations (Edmunds et al., 2006), participation in PA for

3 intrinsic reasons seems to play an important role in the long-term maintenance of PA

4 (Teixeira et al., 2010). Longitudinal research is needed to explore the precise role of the

5 various self-determined regulations in the adoption and maintenance of an active lifestyle.

6 Furthermore, contrary to our hypothesis and some earlier work (e.g., Edmunds et al.,

7 2007), no significant relationship could be demonstrated between introjection and

8 participation in PA. In their review of the literature, Teixeira, Carraca et al. (2012) reported

9 the inconsistency of previous results regarding such a relationship. Some studies have reported a positive correlation (e.g., Edmunds et al., 2007), others a negative correlation (e.g.,

Wilson, Rodgers, Fraser, and Murray, 2004) and still others have reported a null relationship (e.g., Wilson et al., 2006). In light of these mixed results, the conditions and the publics for which introjection is associated with PA need to be investigated in future research.

\section{Mediating role of motivational regulations in the relationship between psychological needs}

satisfaction and $P A$

The mediation analyses conducted through the Preacher and Hayes (2008)

bootstrapping procedure have generally confirmed our hypotheses regarding the mediating role of certain regulations in the relationship between the satisfaction of psychological needs and PA. More specifically, the analyses show that external and identified regulations fully mediate the relationship between the satisfaction of the need for autonomy and PA. The more the adolescents felt that their need for autonomy was satisfied, the higher their identified regulation and the lower their external regulation. In turn, these regulations were, respectively, positively and negatively associated with PA (see Figure 2). On the other hand, external and identified regulations also fully mediate the relationship between the satisfaction of needs for relatedness and PA. However, their effect is opposite: the satisfaction of needs 
1 for relatedness is positively related to identified regulation; itself positively related to PA and

2 from another side, the satisfaction of the need for relatedness is positively related to external

3 regulation, which is negatively related to PA (see Figure 2). Ultimately, the relationship

4 between the need for relatedness and PA are close to null because these two effects tend to

5 cancel each other out. Finally, external regulation partially mediates the relationship between

6 perceived self-efficacy and PA: the more the latter is satisfied, the lower the external

7 regulation; in return, the higher this regulation, the lower the PA. However, once the

8 regulations are controlled, perceived self-efficacy still predicted PA. This partial mediation

9 can be explained in the light of certain work by which the feeling of competence / self-

efficacy can be at the same time a direct antecedent - acting on the amount of effort and time

invested in the activity (Bandura, 1997) - and indirect of PA, through its impact on

participants' motivational regulations (e.g., Edmunds et al., 2006). It should be noted that

earlier work conducted with obese adults (e.g., Edmunds et al., 2007, Silva et al., 2010)

reported no direct relationship between the need for competence and PA. As motivational

antecedents to participation may change with age (Brunet and Sabiston, 2011), an interesting perspective for future work would be to compare the relationships between the various variables of the motivational sequence proposed by SDT in relation to the age of obese populations.

\section{Limits and perspectives}

Several limitations to this study deserve to be mentioned. First, the self-reported nature of the PA data is likely to limit the validity of the results (Buchowski, Townsend, Chan, Acra, and Sun, 1999). In fact, the sample in this study was composed exclusively of obese adolescents in obesity treatment programs, who were therefore strongly encouraged to adopt an active lifestyle. The particularly high level of PA reported by participants (i.e., $M=6$ hours and 18 minutes of PA per week) may be partly due to a social desirability bias 
1 (McMurray et al., 2008). The use of "direct" measurement (e.g., accelerometers) is therefore

2 to be considered in future research. Secondly, participation in this study was on a voluntary

3 basis, the existence of a "self-selection" bias cannot be excluded and may also partially

4 explain this trend. Thirdly, the satisfaction of the need for competence was measured through

5 perceived self-efficacy in PA (Bandura, 1997). While the feeling of competence is connected

6 to the feeling of being effective in producing the desired behavior (Deci, 1975; Deci and

7 Ryan, 2000), it cannot be reduced to this alone. It would be interesting, in future work, to use

8 scales that measure other aspects of the need for competence (e.g., a feeling of overcoming

9 challenges when doing PA). Fourthly, the relatively small size of the sample (125

participants) represented a limit to the scope for analysis. Recruiting larger samples in future work would allow all the relationships to be tested in a single model, and in particular through structural equation modeling. Finally, the transversal nature of this study does not allow causal relationships to be established between the variables. The results observed need to be confirmed by the implementation of experimental and / or longitudinal protocols especially to consider the impact of changes to the various variables over time.

Despite these limitations, this study has identified some motivational characteristics associated with PA in obese adolescents. Several recommendations can - carefully - be extracted from this work. Firstly, health professionals would benefit from taking into account the type of motivation affecting their patients, in addition to the stage of change in which they find themselves. In fact, while stage of change evaluation (see Prochaska, Diclemente and Nocross, 1992) is recommended today in the management of obesity in order to assess the "level" of patients' motivation in respect of health behavior (Durer-Schutz and Schutz, 2009), SDT is proving to be complementary to this approach by specifying the forms of motivation that are associated with long-term behavior and those that are not. For example, obese teenagers at the "action" stage (i.e., participation in PA for less than 6 months) should show a 
1 considerable "quantity" of motivation (Prochaska et al., 1992). However, as this study

2 demonstrates, if their participation in PA is done to please significant others (i.e., external

3 regulation) rather than the perceived usefulness or importance of this behavior (i.e., identified

4 regulation) their investment will remain modest. Other studies have also shown that self-

5 determined forms of motivation towards PA predict the progression of individuals through the

6 various stages of change (eg, Fortier, Sweet, Tulloch, Blanchard, Sigal, Kenny, and Gleid,

7 2011). Thus, a more qualitative evaluation of motivation, in addition to the stages of change,

8 could allow health professionals to better define the motivational characteristics of obese

9 patients and thus treat them more effectively.

Moreover, this study has also shown the relationships that exist between psychological needs - especially those of autonomy and competence - and regulations that predict PA.

Health professionals should therefore promote behaviors likely to fulfill the psychological needs of obese adolescents which have been identified in the literature (see Sarrazin et al., 2011, for a review of the literature): (1) nurture / encourage internal motivational resources (i.e., encourage individual's initiatives by identifying and soliciting their interests and preferences), (2) use informational language (i.e., limit criticism and moralizing in favor of sincere dialogue aimed at taking stock of problems met or progress made), (3) provide a rationale (i.e., explain the value, the meaning, the usefulness or the importance of a behavior), (4) recognize and accept negative effects (i.e., listen to and recognize an individual's point of view, and any difficulties or resistance they may encounter), and (5) give real choices (i.e., allow individuals to be part of the decision-making process and make choices that reflect their values, goals, interests or preferences). 
2 1. The positive and significant correlation between the three needs ( $r$ between .33 and $.41, p$

$3<.05$, see Table 2) on the one hand, and the positive relationship between the satisfaction of

4 the need for relatedness and external regulation $(\beta=.21, p<.05)$, while the bivariate

5 correlation between these two variables is null $(r=.03)$ on the other, suggest the presence of a

6 "suppression effect" (MacKinnon, Krull, and Lockwood , 2000). To confirm the presence of

7 such an effect, a further multiple regression analysis was carried out, without the need for

8 relatedness. Model results with and without the need for relatedness were then compared

9 (Pandey and Elliott, 2010). The inclusion of the need for relatedness causes an increase in the 10 variance explained by the model (adjusted $R^{2}=.22 \mathrm{vs} . .17$ ) and the strength of the 11 relationship between the satisfaction of the need for autonomy $(\beta=-.27, v s . .-.22, p<.01)$ 12 and perceived self-efficacy and $(\beta=-.18 v s .-.12, p<.01)$ and external regulation. These 13 results confirm the suppressive effect of the need for relatedness in the relationship between 14 satisfaction of psychological needs and external regulation (Pandey and Elliot, 2010): the 15 strength of perceived autonomy and perceived self-efficacy is artificially reduced when the 16 satisfaction of the need for relatedness is not controlled. 


\section{References}

Bandura, A. (1997). Self efficacy: The exercise of control. New York: Freeman \& Co.

Baron, R., Kenny, D. (1986). The moderator-mediator variable distinction in social psychological research: Conceptual, strategic, and statistical considerations. Journal of Personality and Social Psychology, 51, 1173-1182.

Bateman, R. (2012). The role of psychological need-thwarting in the experience of disordered eating symptoms: A diary study. Doctoral dissertation (not published). University of Rochester.

Brunet, J., Sabiston, C. M. (2011). Exploring motivation for physical activity across the adult lifespan. Psychology of Sport and Exercise, 12, 99-105.

Buchowski, M. S., Townsend, K. M., Chen, K. Y., Acra, S. A., Sun, M. (1999). Energy expenditure determined by self-reported physical activity is related to body fatness. Obesity Research, 7, 23-33.

Cheval, B., Sarrazin, P. (2011). Vers la construction d'un Outil de Mesure de la Satisfaction et de la Menace des Besoins Psychologiques Fondamentaux dans le domaine du sport [Toward the construction of a questionnaire measuring satisfaction and threat of basic psychological needs in the sport domain]. Actes du XIVème Congrès International de l'Association des Chercheurs en Activités Physiques et Sportives (ACAPS) [Proceedings of the XIV congress of the Association of Researcher in Physical Activity and Sport] (pp. 216-217). Rennes, France.

Cohen J., Cohen P. (1983). Applied Multiple Regression/Correlation Analysis for the Behavioral Sciences. Lawrence Erlbaum Associates: Hillsdale, NJ.

Crocker, P. R., Bailey, D. A., Faulkner, R. A., Kowalski, K. C., McGrath, R. (1997). Measuring general levels of physical activity: Preliminary evidence for the Physical Activity Questionnaire for Older Children. Medicine and Science in Sports and 
Exercise, 29, 1344-1349.

Deci, E. (1975). Intrinsic motivation. New York: Plenum.

Deci, E. L., Ryan, R. M. (2002). Handbook of Self-Determination Research. Rochester, New York: University of Rochester Press.

Deci, E. L., Ryan, R. M. (2000). The 'what' and 'why' of goal pursuits: Human needs and the self-determination of behavior. Psychological Inquiry, 11, 227-268.

Durrer-Schutz, D., Schutz, Y. (2009). Comment aborder l'éducation thérapeutique d'un patient obèse ? La motivation du patient et du médecin: une des clefs du succès thérapeutique? [How should we approach the educational therapy of the obese patient? Are patient and doctor motivation the key to success?]. Obésité , 4, 204-209.

Eagle, T. F., Gurm, R., Goldberg, C. S., DuRussel-Weston, J., Kline-Rogers, E., Palma-Davis, L., Aaronson, S., Fitzgerald, C. M., Mitchell, L. R., Rogers, B., Bruenger, P., Jackson, E. A., Eagle, K. A. (2010). Health status and behavior among middle-school children in a midwest community: What are the underpinnings of childhood obesity? American Heart Journal, 160, 1185-1189.

Edmunds, J., Ntounamis, N., Duda, J. L. (2006). A test of self determination theory in the exercise domain. Journal of Applied Social Psychology, 36, 2240-2265.

Edmunds, J., Ntounamis, N., Duda, J. L. (2007). Adherence and well being in overweight and obese patients referred to an exercise on prescription scheme: A self-determination theory perspective. Psychology of Sport and Exercise, 8, 722-740.

Everett, B., Salamonson, Y., Davidson, P. M. (2009). Bandura's exercise self-efficacy scale: validation in an Australian cardiac rehabilitation setting. International Journal of Nursing Studies, 46, 824-829. 
Fortier, M. S., Sweet, S. N., O'Sullivan, T. L., Williams, G. C. (2007). A self-determination process model of physical activity adoption in the context of a randomized controlled trial. Psychology of Sport and Exercise, 8, 741-757.

Fortier, M. S., Sweet, S. N., Tulloch, H., Blanchard, C. M., Sigal, R. J., Kenny, G. P., Reid, R. D. (2011). Self-determination and exercise stages of change: results from the Diabetes Aerobic and Resistance Exercise trial. Journal of Health Psychology, 17, 87-99.

Groupe d'expertise collective de l'Inserm. (2007). Prise en charge chez l'adolescent en France [Care of adolescent in France]. Obésité, 2, 88-94.

Hagger, M. S., Chatzisarantis, N. L., Harris, J. (2006). The process by which relative autonomous motivation affects intentional behavior: Comparing effects across dieting and exercise behaviors. Motivation and Emotion, 30, 306-320.

Koestner, R., Losier, G. F. (2002). Distinguishing three ways of being highly motivated: A closer look at introjection, identification, and intrinsic motivation. In E. L. Deci, R. M. Ryan (Eds.), Handbook of self-determination research. Rochester, NY: University of Rochester Press.

Kowalski, K. C., Crocker, P. R., Kowalski, N. (1997). Convergent validity of the physical activity questionnaire for adolescents. Pediatric Exercise Science, 9, 342-352.

MacKinnon, D. P., Krull, J. L., Lockwood, C. M. (2000). Equivalence of the mediation, confounding and suppression effect. Prevention Science, 1, 173-181.

McMurray, R. G., Ward, D. S., Elder, J. P., Lytle, L. A., Strikmiller, P. K., Baggett, C. D., Young, D. R. (2008). Do overweight girls overreport physical activity? American Journal of Health Behavior, 32, 538-546.

Markland, D., Tobin, V. (2004). A modification to the Behavioural Regulation in Exercise Questionnaire to include an assessment of amotivation. Journal of Sport and Exercise Psychology, 26, 191-196. 
Ministère de l'Emploi et de la Solidarité, Direction générale de la Santé. (2001). Programme National Nutrition Santé (PNNS): 2001-2005 [National program of nutrition and health:2001-2005]. Cahier de Nutrition et de Diététique, 36, 207-216.

Ng, J., Thogersen-Ntoumani, E. C., Ntoumanis, N., Deci, E. L., Ryan, R., Duda, J., Williams, G.C. (2012). Self-Determination Theory applied to health contexts: A meta-analysis. Perspectives on Psychological Science , 7, 325-340.

Pandey, S., Elliott, W. (2010). Suppressor variables in social work research: Ways to identify in multiple regression models. Journal of the Society for Social Work and Research, 1, $28-40$.

Parizkova, J., Hills, A. (2001). Childhood obesity: prevention and management . Boca Rotan, Florida: CRC Press.

Pi-Sunyer, F. X. (2002). Glycemic index and disease . American Journal of Clinical Nutrition, 76, 290S-298S.

Preacher, K. J., Hayes, A. F. (2008). Asymptotic and resampling strategies for assessing and comparing indirect effects in multiple mediator models. Behavior Research Methods, $40,879-891$.

Prochaska, J. O., Di Clemente, C. C., Nocross, J. C. (1992). In search of how people change: applications to addictive behaviour. American Psychologist, 47, 1102-1114.

Reeve, J., Nix, G., Hamm, D. (2003). Testing models of the experience of self-determination in intrinsic motivation and the conundrum of choice. Journal of Educational Psychology, 95, 375-392.

Rolland-Cachera, M. F., Thibault, H. (2002). Définition et évolution de l'obésité infantile [Definition and evolution of pediatric obesity]. Journal de Pédiatrie et de Périculture, $15,448-453$. 
Quested, E., Bosch, J. A., Burns, V. E., Cumming, J., Ntoumanis, N., Duda, J. (2011). Basic psychological need satisfaction, stress-related appraisals, and dancers' cortisol and anxiety responses. Journal of Sport and Exercise Psychology, 33, 828-846.

Ryan, R. M., Connell, J. P. (1989). Perceived locus of causality and internalization: Examining reasons for acting in two domains. Journal of Personality and Social Psychology, 57, 749-761.

Ryan, R. M., Deci, E. L. (2000). Self-determination theory and the facilitation of intrinsic motivation, social development, and well-being. The American Psychologist, 55, 68-78.

Salavane, B., Peneau, S., Rolland-Cachera, M.-F., Hercberg, S., Castetbon, K. (2009). Stabilization of overweight prevalence in French children between 2000 and 2007. International Journal of Pediatric Obesity, 4, 66-72.

Sarrazin, P., Pelletier, L., Deci, E., Ryan, R. (2011). Nourrir une motivation autonome et ses conséquences positives dans différents milieux de vie: les apports de la théorie de l'autodétermination [Promoting autonomous motivation and its positive consequences in various life domains:contributions of the self-determination theory]. In C. MartinKrumm, C. Tarquinio, Traité de psychologie positive. Fondements théoriques et implications pratiques [Treaty of positive psychology. Theoretical fundations and practical implications] (pp. 273-312). Bruxelles: de Boeck.

Shrout, P. E., Bolger, N. (2002). Mediation in experimental and non-experimental studies: New procedures and recommendations. Psychological Methods, 7,422-445.

Silva, M. N., Markland, D. A., Vieira, P. N., Coutinho, S. R., Carraca, E. V., Palmeira, A. L., Minderico, C. S., Matos, M. G., Sardinha, L. B., Teixeira, P., J. (2010). Helping overweight women become more active: Need support and motivational regulations for different forms of physical activity. Psychology of Sport and Exercise, 11, 591-601. 
Teixeira, P. J., Carraça, E. V., Markland, D., Silva, M. N., Ryan R, M. (2012). Exercise, physical activity, and self-determination theory: A systematic review. International Journal of Behavioral Nutrition and Physical Activity , 9, 78.

Teixeira, P. J., Silva, M.N., Coutinho, S.R., Palmeira, A.L., Mata, J., Vieira, P.N., Carraça, E.V., Santos, T.C., Sardinha, L.B. (2010). Mediators of weight loss and weight loss maintenance in middle-aged women. Obesity, 18, 725-735.

Thøgersen-Ntoumani, C., Ntoumanis, N. (2006). The role of self-determined motivation in the understanding of exercise-related behaviours, cognitions and physical self-evaluations. Journal of Sports Sciences, 24, 393-404.

Wilson, P. M., Rodgers, W. M., Loitz, C. C., Scime, G. (2006). "It's who I am...really!". The importance of integrated regulation in exercise contexts. Journal of Applied Biobehavioral Research, 11, 79-104.

Wilson, P. M., Rodgers, W. M., Fraser, S. N., Murray, T. C. (2004). Relationships between exercise regulations and motivational consequences in university students. Research Quarterly for Exercise and Sport, 75, 81-91.

Wilson, P. M., Rogers, W. T., Rodgers, W. M., Wild, T. C. (2006). The psychological need satisfaction in exercise scale. Journal of Sport and Exercise Psychology, 28, 231-251.

World Health Organisation. (2012). Social determinants of health and well-being among young people: Health Behaviour in School-Aged Children (HBSC) study. Geneva, Switzerland.

Wu, T., Gao, X., Chen, M., \& van Dam, R. M. (2009). Long-term effectiveness of diet plus exercise versus diet-only interventions for weight loss: a meta-analysis. Obesity Reviews, 10, 313-323. 


\section{Table 1:}

Hypothesis on the relationships between the satisfaction of psychological needs and motivational regulations.

Hypothèses concernant les liens entre satisfaction des besoins psychologiques et régulations motivationnelles.

\begin{tabular}{l|cccccc}
\hline & $\begin{array}{c}\text { Intrinsic } \\
\text { motivation }\end{array}$ & $\begin{array}{c}\text { Integrated } \\
\text { regulation }\end{array}$ & $\begin{array}{c}\text { Identified } \\
\text { regulation }\end{array}$ & $\begin{array}{c}\text { Introjected } \\
\text { regulation }\end{array}$ & $\begin{array}{c}\text { External } \\
\text { regulation }\end{array}$ & Amotivation \\
\hline Perceived autonomy & ++ & ++ & + & - & - & -- \\
Perceived competence & ++ & + & $+/ 0$ & $-/ 0$ & - & -- \\
Perceived relatedness & $+/ 0$ & + & + & + & - & -- \\
\hline
\end{tabular}

Note. Plus sign means that the satisfaction of the need is positively related to the regulation, whether it is moderately $(+)$ or strongly $(++)$; minus sign means that the satisfaction of the need is negatively related to the regulation, whether it is moderately $(-)$ or strongly $(--)$; the sign 0 means that the satisfaction of the need is not related to the regulation. 


\section{Table 2:}

Descriptive statistics and correlation coefficients.

Statistiques descriptives et coefficients de corrélation.

\begin{tabular}{|c|c|c|c|c|c|c|c|c|c|c|c|c|c|}
\hline Variables & 1 & 2 & 3 & 4 & 5 & 6 & 7 & 8 & 9 & 10 & 11 & 12 & 13 \\
\hline 1. Sex & - & & & & & & & & & & & & \\
\hline 2. Age & -.06 & - & & & & & & & & & & & \\
\hline 3. BMI (Z-score) & -.04 & -.16 & - & & & & & & & & & & \\
\hline 4. Perceived autonomy & .10 & -.09 & -.06 & .81 & & & & & & & & & \\
\hline 5. Perceived self-efficacy & .04 & .05 & $-.23 * *$ & $.41 * *$ & .92 & & & & & & & & \\
\hline 6. Perceived relatedness & $.20^{*}$ & -.13 & $-.27 * *$ & $.35^{* *}$ & $.33 * *$ & .88 & & & & & & & \\
\hline 7. Intrinsic motivation & $.33 * *$ & .01 & -.14 & $.67 * *$ & $.37 * *$ & $.45^{* *}$ & .88 & & & & & & \\
\hline 8. Integrated regulation & $.31 * *$ & -.07 & -.17 & $.56^{* *}$ & $.24 * *$ & $.54 * *$ & $.72 * *$ & .83 & & & & & \\
\hline 9. Identified regulation & $.22 *$ & -.10 & -.13 & $.46 * *$ & $.33 * *$ & $.43 * *$ & $.57 * *$ & $.78 * *$ & .81 & & & & \\
\hline 10. Introjected regulation & .05 & 01 & .07 & $.25^{* *}$ & -.03 & .17 & $.29 * *$ & $.47 * *$ & $.57 * *$ & .65 & & & \\
\hline 11. External regulation & $.22 *$ & -.03 & $.26 * *$ & $-.27 * *$ & $-.28 * *$ & .03 & -.01 & .02 & -.05 & $.27 * *$ & .70 & & \\
\hline 12. Amotivation & .03 & -.11 & .14 & $-.44 * *$ & $-.43 * *$ & -.18 & $-.49 * *$ & $-.41 * *$ & $-.52 * *$ & -.13 & $.34 * *$ & .70 & \\
\hline 13. PA length & $.23^{*}$ & .03 & $-.24 * *$ & $.36 * *$ & $.42 * *$ & $.37 * *$ & $.40 * *$ & $.43 * *$ & $.44 * *$ & .11 & $-.23 * *$ & $-.24 * *$ & - \\
\hline$M$ & - & 14.82 & 3.47 & 5.41 & 82.40 & 5.68 & 5.33 & 4.53 & 5.05 & 3.44 & 2.99 & 1.50 & 6.30 \\
\hline SD & - & 2.69 & 1.26 & 1.30 & 22.55 & 1.32 & 1.53 & 1.69 & 1.41 & 1.35 & 1.45 & 0.87 & 4.11 \\
\hline Kurtosis & - & - & 0.05 & -0.01 & 1.14 & 1.54 & -0.11 & -1.16 & -0.78 & -0.60 & -0.34 & 4.06 & -0.13 \\
\hline Skewness & - & - & 0.76 & -0.70 & -1.35 & -1.26 & -0.83 & -0.12 & -0.33 & 0.37 & 0.42 & 2.10 & 0.62 \\
\hline
\end{tabular}

Note. All variables were measured on 7-point scales with the exception of perceived self-efficacy (100-point scale). PA is measured in hours per week. Sex id coded (1) girl,

(2) boy. $\mathrm{M}=$ Mean. $\mathrm{SD}=$ Standard deviation. Cronbach's alpha coefficients are presented in the diagonal. * $p<.05, * * p<.01$. 


\section{Table 3:}

Summary of multiple regression analyses measuring the relationships between satisfaction of psychological needs and motivational regulations.

Synthèse des analyses de régressions multiples mesurant les relations entre la satisfaction des besoins psychologiques et les régulations motivationnelles.

\begin{tabular}{|c|c|c|c|}
\hline & Adjusted $R^{2}$ & $\beta$ & $t$ \\
\hline \multicolumn{4}{|l|}{ Amotivation } \\
\hline$F(5,118)=9.03, p<.001$ & .24 & & \\
\hline BMI (Z-score) & & .06 & 0.76 \\
\hline Sex & & .07 & 0.93 \\
\hline Perceived autonomy & & -.33 & $-3.73 * *$ \\
\hline Perceived self-efficacy & & -.29 & $-3.26 * *$ \\
\hline Perceived relatedness & & .03 & 0.40 \\
\hline \multicolumn{4}{|l|}{ External regulation } \\
\hline$F(5,118)=8.03, p<.001$ & .22 & & \\
\hline BMI (Z-score) & & .26 & $3.17 * *$ \\
\hline Sex & & .22 & $2.77 * *$ \\
\hline Perceived autonomy & & -.27 & $-3.08 * *$ \\
\hline Perceived self-efficacy & & -.18 & $-2.02 *$ \\
\hline Perceived relatedness & & .21 & $2.36^{*}$ \\
\hline \multicolumn{4}{|l|}{ Introjected regulation } \\
\hline$F(5,118)=2.68, p<.05$ & .06 & & \\
\hline BMI (Z-score) & & .08 & 0.92 \\
\hline Sex & & .00 & 0.03 \\
\hline Perceived autonomy & & .26 & $2.69 * *$ \\
\hline Perceived self-efficacy & & -.17 & $-1.71 \mathrm{t}$ \\
\hline Perceived relatedness & & .15 & 1.51 \\
\hline \multicolumn{4}{|l|}{ Identified regulation } \\
\hline$F(5,118)=10.89, p<.001$ & .28 & & \\
\hline BMI (Z-score) & & -.00 & -0.09 \\
\hline Sex & & .13 & 1.69 \\
\hline Perceived autonomy & & .30 & $3.52 * *$ \\
\hline Perceived self-efficacy & & .11 & 1.35 \\
\hline Perceived relatedness & & .25 & $2.87 * *$ \\
\hline \multicolumn{4}{|l|}{ Integrated regulation } \\
\hline$F(5,118)=22.66, p<.001$ & .46 & & \\
\hline BMI (Z-score) & & -.05 & -0.82 \\
\hline Sex & & .19 & $2.95 * *$ \\
\hline Perceived autonomy & & .44 & $5.87 * *$ \\
\hline Perceived self-efficacy & & .07 & 1.03 \\
\hline Perceived relatedness & & .35 & $4.71 * *$ \\
\hline \multicolumn{4}{|l|}{ Intrinsic motivation } \\
\hline$F(5,118)=30.22, p<.001$ & .54 & & \\
\hline BMI (Z-score) & & -.03 & -0.51 \\
\hline
\end{tabular}


Sex

$.23 \quad 3.77 * *$

Perceived autonomy

.55

$7.99 * *$

Perceived self-efficacy

.05

0.95

Perceived relatedness

.17

2.53*

Note: $\mathrm{t} p<.10,{ }^{*} p<.05,{ }^{* *} p<.01$ 


\section{Table 4:}

Summary of multiple regression analysis measuring the relationships between motivational regulations and $\mathrm{PA}$.

Synthèse de l'analyse de régression multiple mesurant les relations entre les régulations motivationnelles et l'AP.

\begin{tabular}{lccc}
\hline & Adjusted $R^{2}$ & $\beta$ & $t$ \\
\hline$F(8,117)=6.99, p<.001$ & .27 & & \\
BMI (Z-score) & & -.10 & -1.26 \\
Sex & & .09 & 1.05 \\
Amotivation & -.14 & -1.41 \\
External regulation & & -.21 & $-2.37^{*}$ \\
Introjected regulation & -.11 & -1.11 \\
Identified regulation & .36 & $2.51^{*}$ \\
Integrated regulation & .06 & 0.45 \\
Intrinsic motivation & & .21 & $1.85^{\mathrm{t}}$ \\
\hline
\end{tabular}

Note: $\mathrm{t} p<.10,{ }^{*} p<.05,{ }^{* *} p<.01$

\section{Table 5:}

Estimation of indirect effects (specifics and totals) of each psychological need on PA length through motivational regulations (bootstrap analyses).

Estimation des effets indirects (individuels et totaux) de chaque besoin psychologique sur la durée d'AP par l'intermédiaire des régulations motivationnelles (analyses bootstrap).

\begin{tabular}{|c|c|c|c|c|}
\hline & & & $95 \% \mathrm{~b}$ & orrected CI \\
\hline & & B & Lower bound & Upper bound \\
\hline Bootstrap analysis for pe & & & & \\
\hline Intrinsic motivation & & 0.11 & -0.30 & 0.55 \\
\hline Identified regulation & & $0.21 *$ & 0.04 & 0.50 \\
\hline External regulation & & $0.16^{*}$ & 0.02 & 0.37 \\
\hline Total effect & & $0.48 *$ & 0.05 & 1.04 \\
\hline Effect ratio & 0.87 & & & \\
\hline Bootstrap analysis for pe & & & & \\
\hline Intrinsic motivation & & 0.001 & -0.002 & 0.01 \\
\hline Identified regulation & & 0.005 & -0.001 & 0.02 \\
\hline External regulation & & $0.006 *$ & 0.0002 & 0.02 \\
\hline Total effect & & $0.012 *$ & 0.0003 & 0.03 \\
\hline Effect ratio & 0.25 & & & \\
\hline Bootstrap analysis for pe & & & & \\
\hline Intrinsic motivation & & 0.04 & -0.08 & 0.26 \\
\hline Identified regulation & & $0.18 *$ & 0.03 & 0.48 \\
\hline External regulation & & $-0.13^{*}$ & -0.35 & -0.001 \\
\hline Total effect & & 0.09 & -0.18 & 0.50 \\
\hline Effect ratio & 0.17 & & & \\
\hline
\end{tabular}


Note $. \mathrm{B}=$ Unstandardized regression coefficient. $\mathrm{CI}=$ Confidence interval. $*=p<.05$. For each analysis, sex, BMI and the two other psychological needs not directly involved in the mediation were used as control variables. 
Figure 1 :

Presentation of the motivational sequence of the self-determination theory.

Présentation de la séquence motivationnelle de la théorie de l'autodétermination.

Figure 2:

Summary results of mediation analysis. Only significant pathways are mentioned. Coefficients are given after having controlled for the sex and the BMI (not mentioned in the figure). Pathways in bold represent significant mediations. Unstandardized coefficients of bootstrap analyses are in brackets. t $p<.10, * p<.05, * * p<.01$.

Synthèse des résultats des analyses de médiation. Seules les pistes significatives sont mentionnées. Les coefficients sont donnés après avoir contrôlé le sexe et l'IMC (non mentionnés sur la figure). Les pistes en gras correspondent aux médiations identifiées. Les coefficients non standardisés des analyses bootstrap sont entre parenthèses. $\mathrm{t} p<.10, * p<.05, * * p<.01$. 
Figure 1

Basic psychological

needs

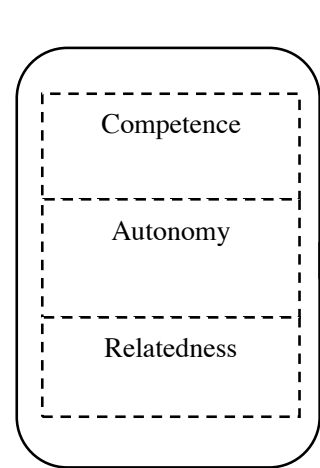

Types of motivational regulations
Outcomes

Physical activity

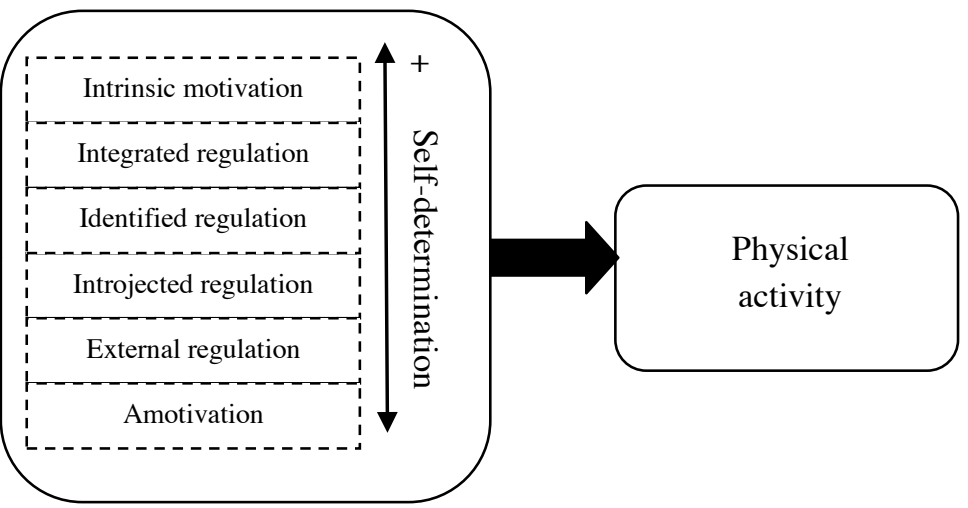




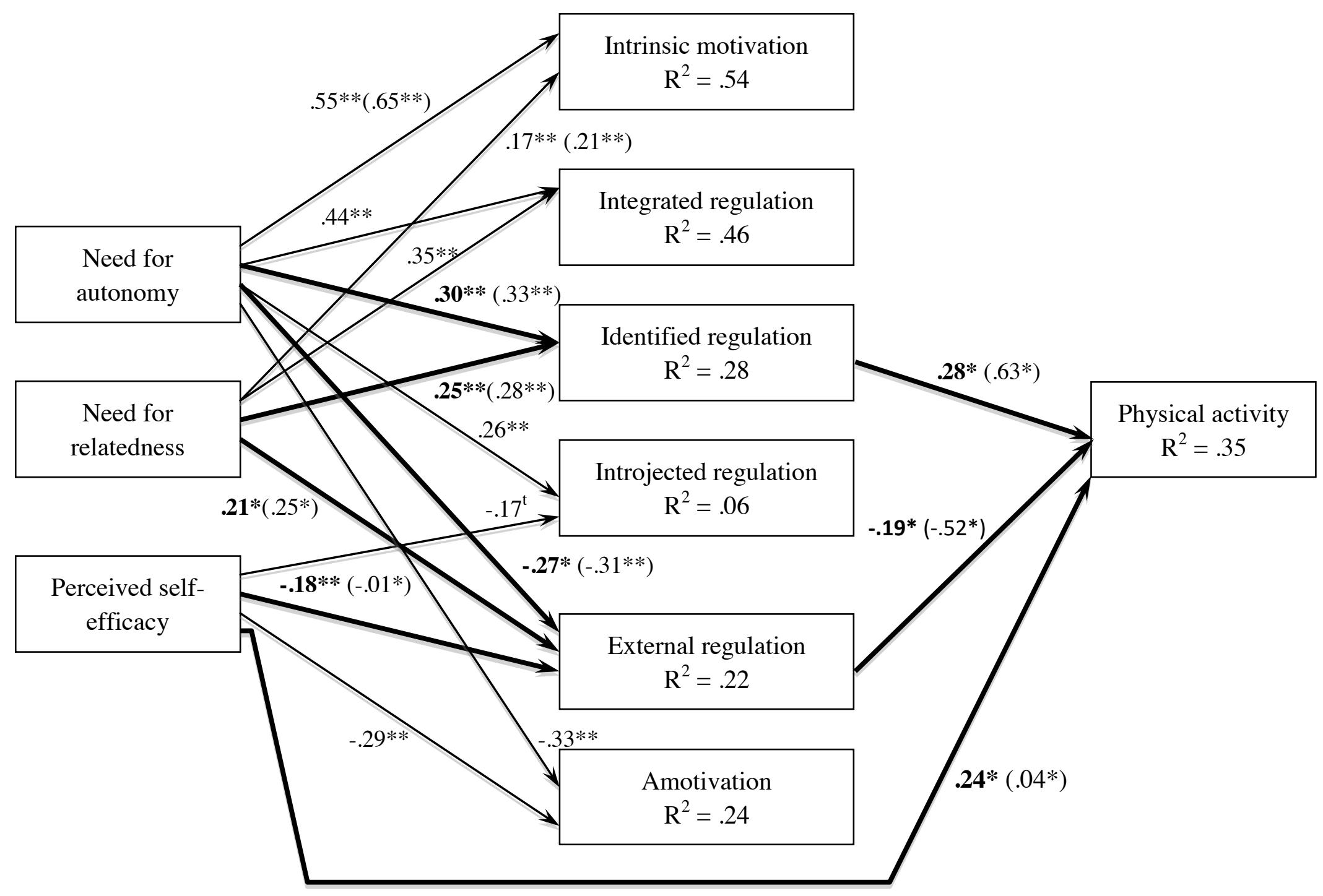

